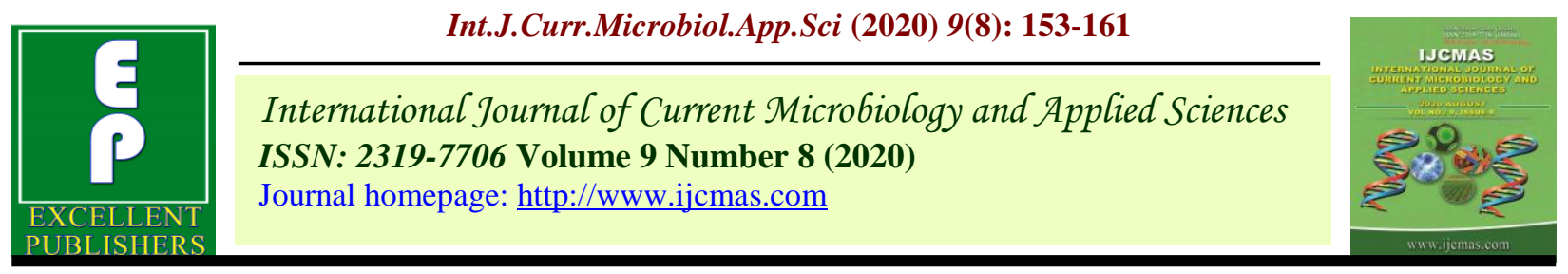

Review Article

https://doi.org/10.20546/ijcmas.2020.908.016

\title{
Diallel Crossing in Farm Animals and Poultry: A Review
}

\author{
Ashutosh Dubey ${ }^{*}$, Asit Jain, Deepti Kiran Barwa, Aayush Yadav, \\ Manish Kumar Bobade, Vikas Kumar, Anupam Soni and Arvind K. Nanadanwar \\ College of Veterinary Sciences \& Animal Husbandry, CGKV, Anjora, Durg (C.G.), India \\ *Corresponding author
}

\section{A B S T R A C T}

\begin{tabular}{|l|}
\hline K e y w o r d s \\
$\begin{array}{l}\text { Diallel cross, } \\
\text { quantitative traits, } \\
\text { additive and } \\
\text { dominance genetic } \\
\text { effects }\end{array}$ \\
\hline Article Info \\
\hline $\begin{array}{l}\text { Accepted: } \\
\text { 10 July } 2020 \\
\text { Available Online: } \\
\text { 10 August } 2020\end{array}$ \\
\hline
\end{tabular}

A diallel cross is a mating scheme which has been utilized for investigating the genetic underpinnings of traits with quantitative nature. In field of animal and poultry breeding, it has vast scope for improving the production performances. To exploit the full advantage of diallel crossing with ease, the different modifications viz. full, partial, incomplete and complete diallel crossing had been developed. The genetic basis for improvement in performance due to diallel cross is attributed to two main factors i.e. direct genetic effects (due to additive gene action) and various dominance genetic effects (due to non-additive gene action). Hence, the utilization of various effects i.e. direct genetic effects, reciprocal effects, utilization of effects due to general/specific combining ability, maternal and heterotic effects should be performed. However, the rate of genetic improvement varies with the different species of livestock i.e. higher rate on animals which are prolific/shorter generation interval while lower rate with animals of shorter generation interval. Thus, this tool of genetic improvement should be judiciously used considering the socio-economic and cultural values of livestock in different societies or regions.

\section{Introduction}

To effectively mitigate the tremendous pressure on livestock/poultry sector to fulfil the gap between demand and supply of livestock/poultry food products, the genetic improvement is one of the methods that can be employed to improve the production efficiency of livestock/poultry. In most of the farm animals/poultry, crossbreeding and different approaches for combining ability is generally employed to utilize the advantage of heterosis and to make a perfect combination of different traits which are of economic importance (Razuki and Al-Shaheen, 2011).
In species with high prolificacy and short generation interval, such as swine and poultry, the diallel crossing system is most commonly used. A diallel cross is a scheme of mating which has been utilized for investigating the genetic underpinnings of traits with quantitative nature (Crusio et al., 1984). In it, all the available parents are crossed in such a way that so as to make hybrids in all possible combinations, with the main aim to identify the genetic makeup with most profitable combination (Orengo et al., 2009). Since, it is difficult to manage full diallel crosses when the number of parents are large, thus in such cases, several 
modifications can be done on the basis of number of parents utilized for diallel crossings and inclusion of reciprocal $F_{1}$ crossing, it may be full diallel crossing (when both the parents and reciprocal $\mathrm{F}_{1}$ crosses were used), full diallel with reciprocal $F_{1}$ crosses but without inclusion of parents, partial diallel (It involves only certain crosses from all those possible total combinations using both male and female parents but omitting self's and reciprocals; Kempthorne and Curnow, 1961) or half diallel (Involves all possible crosses between all genotypes using both male and female parents, without involving any reciprocals; Kearsey, 1984).

In case of farm animals, mainly in species like swine and poultry, which are more prolific with shorter generation interval, many researchers have employed the diallel crossing to determine the genetic effects by identifying the most profitable combination of different lines/breeds/strains for a given trait (Okoro, 2012). It also considers the approximate estimation of various parameters that yields additional effects by influencing the expression of genotypes involved in breeding programs viz. reciprocal effects, general and specific combining ability, maternal and heterotic effects.

\section{Utilization of diallel crossing in different species of farm animals and poultry}

\section{In Cattle}

The diallel cross, in usual, from past has been utilized for evaluation of germplasm in cattle, that will be helpful in providing the reliable information about the usefulness of alternative breed stocks and breeding strategy. Therefore, having accurate information of breed composition will be helpful in evaluating the performance of native/pure breeds in comparison to crossbreeds (with varying composition) in a particular environment. Among beef cattle, Gobena et $a l ., 2018$ had observed varying crossbred ratio of 1:1 to $3: 4$ among Taurine:Zebu in different regions of united states. Similarly, Dearborn et al., 1987 had observed significant maternal heterotic effects on pre-weaning calf traits viz. body weight at birth and at 200 days of age, frequency of calving assistance, live calf born and percentage of weaning among Brown swiss, Red poll, Hereford and Angus breed of cattle in a diallel crossing among them.

Among dairy cattle, various efforts had been made since 1968 to utilize diallel crossing. McDowell and McDaniel (1968) had utilized complete diallel crossing of Holstein $(\mathrm{H})$, Ayrshire (A) and Swiss (S) breed and observed $8-10 \%$ heterosis for fat corrected milk in $F_{1}$ generation with $A \times S$ cross and concluded that various crossbreds supersedes purebred Holstein in net return on first lactation. However, Olson et al.(2009) had observed incidences of dystocia, stillbirth, gestation length, and birth weight among Holstein and Jersey in a diallel crossbreeding ( HH, HJ, JH and JJ genetic groups) and had observed highest body weight along with greater chances of dystocia in $\mathrm{HH}$ group while lowest for JJ group. Maltecca et al., (2006) had also reported $1.9 \mathrm{~kg}$ lower body weight for $\mathrm{HJ}$ crosses as compared to $\mathrm{HH}$ crosses.

The ease in calving and better performances may be due to the direct additive effects, heterotic effects in $F_{1}$ generation, recombination effects or due to the maternal effects (genetic/heterotic) that varies from breed to breed. Thus, due consideration should be given on selection of breeds while formulating any breeding plans. As compared to the swine and poultry, very little research work had been conducted on large ruminants which may be due to the large generation interval of these species of livestock. 


\section{In Small Ruminants (Sheep \& Goats)}

Otuma and Nwakpu (2007) for evaluation of growth improvement program of indigenous Nigerian West African dwarf goat had conducted complete diallel crosses among West african dwarf goat (WADG) and Red sokoto goat (RSG) for pre-weaning weights (PW) and two linear body measurements viz. height at withers (HW) and length of body (BL). The RSG-F 1 (RSG-WADG) was found to be superior and best for growth improvement of nigerian west african dwarf goat. Furthermore, Browning and LeiteBrowning (2011) had evaluated genetic effects on pre-weaning kid performance in a complete 3-breed diallel mating scheme (Boer, Kiko and Spanish), where, Kiko breed was found to be superior as compared to Spanish and Boer under humid, subtropical semi-intensive condition.

A complete diallel crossing was performed in Garole sheep of India to evaluate the inheritance of Haemonchus contortus resistance among three different group's viz. resistant, less susceptible and highly susceptible groups, where they had reported less EPG with increase in overall resistance among lambs of $2^{\text {nd }}$ and $3^{\text {rd }}$ generations with respect to their parent generation (Roy et al., 2018). Similarly, Brown and Mayeux (2005), while observing post weaning performance of grazing among hair and wool sheep and their reciprocal crosses in a 3 diallel mating plans (Dorset-St. Croix, Rambouillet-Gulf Coast and Katahdin-Suffolk breeds) and a terminalcross had reported better summer performance of Katahdin x Suffolk diallel than their parental purebreds, which was in accordance with Mavrogenis (1996) who reported positive but small estimates of direct heterosis for post weaning ADG in crosses of Chios and Awassi breeds. However, Rastogi et al., (1975) reported individual heterosis in post weaning ADG for crosses among
Columbia, Suffolk, and Targhee, but it was only around 2 percent above the purebred mean.

\section{In Swine and Poultry}

Since diallel crossing is most commonly and successfully employed in those species which are having high reproductive rates and short generation interval viz. in swine and poultry, hence the utilization of genetic and various non-genetic effects of diallel crossing of this two species has been reviewed separately.

\section{Utilization of genetic effects from diallel crosses}

The various researchers had employed the use of diallel mating for improvement of both productive traits i.e. traits related to morphometry, average daily weight gain/growth rate, body weight at weaning/maturity and reproductive traits viz. litter size and weight at birth, milk production of sow and mothering ability (Garcia-Casco et al., 2012, Okoro 2012, Okoro and Mbajiorgu, 2017a).

Razuki and Al-Shaheen (2011) found that the genetic effect obtained varies with the breeds employed for crossing. In a $3 \times 3$ diallel cross of different breeds viz. Brown line (BR), White leghorn (WL) and New hampshire $(\mathrm{NH})$, the highest body weight was observed for $\mathrm{BR} \times \mathrm{NH}$ cross, while $\mathrm{NH}$ purebred possess maximum body weight among all purebreds at different intervals. However, the age at sexual maturity (ASM) was least for purebred BR followed by WL and NH.

The highest number of eggs was produced WL $x$ NH and it's reciprocal NH x WL cross as compared to other purebred and their crosses. Similarly, purebred WL recorded highest weight of egg as compared to other purebreds. The genetic effect on age at sexual 
maturity and egg production was found to be non-significant, however, such effects were significant on egg weight. One of the possible reasons for significant values is high heritability, with more presence of genes with additive effects.

\section{Utilization of reciprocal effects from diallel crosses}

The reciprocal effects are non-additive genetic effects which are primarily caused due to sex linkage and maternal effects. Most of the researchers had considered common assumption i.e. lack of any differences in diallel cross due to absence of reciprocal effects. However, such effects on the analysis of diallel cross had been observed by Mather and Jinks (1982). Therefore, the quantification of magnitude and nature of reciprocal effect will aids in identification and selection of best genetic group/s for improvement (Iraqi et al., 2007).

The significant reciprocal effects was observed by Duro et al., (2015) in a diallel cross for body weight and some morphometric traits viz. length of ear, tail, snout and body, heart girth, snout circumference and height at withers among Indigenous Nigerian (IN), large white (LW) and landrace breeds. However, Okoro and Mbajiorgu (2017b) had reported no such effects for growth and reproductive traits.

At the time of hatching and during 3 months of age, Musa et al., (2015) had observed significant estimates for reciprocal effects, which implies the presence of sex linked and maternal effects. When crossing was made between normal feathered indigenous chicken of Nigeria/South Africa (N), frizzle (F) and nacked neck birds $(\mathrm{Na})$, they reported superior performance of $\mathrm{NNa}$, which may be supposed due to the effects of maternal origin. However, Cook et al., (1972) suggested that, since the homogametic males possess comparable sex chromosomes, which could be one of the reasons that in reciprocal crosses, differences among male progeny may be attributable to maternal effects and not to sex linkage. The degree of such sex linked effects is supposed to vary by selection of sire breed and dam during planning any crossbreeding programs (Sabri et al., 2000).

\section{Utilization of combining ability effects from diallel crosses}

The combining or nicking ability may be of two type i.e. general combining ability (GCA) or specific combining ability (SCA). The GCA is due to additive gene action while SCA is due to non-additive gene action i.e. includes dominance and Epistatic effects. The analysis of diallel cross provides information on the GCA of parents and SCA of crosses in case of quantitative or complexly inherited traits (Saadey et al., 2008).

Kurnianto et al., (2010) in analysis of partial diallel cross among Duroc, Yorkshire and Landrace, had observed highest GCA in Duroc breed for traits such as litter size/weight at birth, number of nipples, litter size/weight at weaning, average daily gain before/after weaning and body weight at 42 days of age as compared to Yorkshire and Landrace. Similarly, Okoro and Mbajiorgu (2017b) had also observed significant GCA effects for growth and body weight gain traits up to 20 weeks of age among Large white, Landrace and Nigerian indigenous breeds of pig.

The SCA estimates were highest for Duroc $\mathrm{x}$ Yorkshire cross for various production traits viz. weight at birth/at weaning, number of nipples and average daily gain before weaning. However, such estimates for litter size/weight at birth/weaning, post weaning average daily weight gain and body weight at 
42 days of age was highest for Yorkshire $\mathrm{x}$ Landrace crosses. In support to this, Duro et al., (2015) had also observed significant $(\mathrm{P}<0.01)$ effects of SCA on body weight and all morphometric traits, however, no significant effects had been observed for GCA on any of the traits considered, which indicates the non-additive nature of genes governing these traits and concluded to exploit heterosis by planned crossbreeding programs for improvement of these traits.

In a diallel crossing, Musa et al., (2015) reported a significant effect of GCA on expression of body weight at $4^{\text {th }}$ week of age, which may be caused by the action of additive genes.

The significantly higher body weight of frizzle as compared to other genotypes in all ages indicates that frizzle genes present in this genotype have high GCA values, causing increase in body weight. Furthermore, Razuki and Al-Shaheen (2011) had reported varying GCA estimates of age at sexual maturity, egg weight and egg production among three different breeds. Hence, the proper selection of breed could be an important procedure for improvement of such traits.

Similarly, the SCA estimates was reported to be significant and positive only for FrizzleNacked neck cross during $16^{\text {th }}$ and $20^{\text {th }}$ weeks of age, which indicates the presence of nonadditive gene action (Kabir et al., 2012) and is supposed to be improved by utilizing proper crossbreeding programs and managemental practices.

\section{Utilization of maternal effects from diallel crosses}

The maternal effect can be defined as the influence of the environment provided by the mother on the phenotype of her offspring and is long been recognized by quantitative geneticists as an important factor in performance of an offspring (Wolf and Wade, 2009). Females of some species in general and some breeds in particular of different livestock are good mothers while others are poor, and this variability has a genetic basis (Fleming and Kraemer, 2019).

The significant maternal effects was observed by Okoro and Mbajiorgu (2017b) for body weight gain (BWW and BW20) and average daily weight gain (ADG) traits, which was in accordance with Gonzalez-pena et al., (2015) where they observed significant maternal effects for average daily gain, back fat thickness, feed efficiency and carcass lean percent due to semen traits. Similarly, Hsu and Johnson (2015) in large white breed also reported such significant maternal effects on body weight at 180 days (WT180), longissimus muscle area (LMA) and back fat thickness (BF10) traits. Such finding reveals that these traits are influenced by effect of dam and thus, proper selection of dam is important better performance of such traits.

The effect of maternal inheritance on stress responsiveness was reported by Odeh et al., (2003) in a 3x3 factorial design among japanese quail birds with low (LS), random bred (RB) and high stress/cortisone (HS) level in blood. They observed maternal effects responses among all three genotypes with highest maternal effect for HS followed by LS and RB.

The paternal effect is lower $(P<0.05)$ than maternal in RB and LS quail, which may includes effects of sex linkage, environment of incubator, composition of an egg, maternal antibodies and cytoplasmic/mitochondrial inheritances and finally concluded that birds tendency to bear stressors comes from the maternal effects. Similar observations were also reported by other researchers (Jones et al., 1994; Razuki and Al-Shaheen, 2011). 


\section{Utilization of heterotic effects from diallel crosses}

The heterosis is the outcome of non-additive genetic action that animal breeder utilizes for improving the animal's performance in later generation. The selection of parents with greater variability and much intense form of out breeding viz. crossbreeding is the most common method employed for improvement in vitality and performance of livestock through heterosis.

Due to the utilization of non-additive genetic variance by heterosis, the crossbred animals, in general, are superior than purebred animals, particularly, in traits with low heritability such as fitness, survival and reproductive traits (Dubey et al., 2019). While working on different crosses of Iberian pigs, Garcia-casco et al., (2012) had reported significant effect of heterosis on body weight at 420 days of age, however, for daily growth rate, the non-significant effects was observed for first five combinations with significant heterotic effects for rest of the combinations. Among various reproductive traits, they reported a non-significant progeny specific effect of heterosis on traits related to litter size in first and second parities along with highly significant effects at later parities. Similar, significant effect of heterosis was observed by Baas and Christian (1992) on number of piglets born alive and on birth weight of litter, however, such effects were non-significant on milk production and composition. Hence, to exploit the maximum amount of heterosis, the best distantly related parents must be selected and cross breeding programs must be planned in such a way so as to combine the beneficial characteristics of all selected breeds.

The crossbred birds, in general, have higher body weight than purebreds due to positive heterotic effect at different growth stages in chicken (Taha and Abd El-Ghany, 2013). However, Falconer and Mackay (1996) postulated that the adaptability of hybrids will be negligible on crossing of two different populations adapted to different conditions i.e. two genes in opposite direction to each other when comes together, tends to cancel out each effects, thus no heterosis may be observed. In support to this, Odeh et al., (2003) had observed no significant heterosis for plasma cortisone level (an indicator of stress) for any reciprocal crosses, which may be attributed to epistatic interactions. The breed selection and nature of traits considered may be the factor for varying results among researchers.

In conclusion the diallel cross, which involves the crossing of available parents in all possible combinations so as to identify the genetic makeup with better performances. i.e. it is used to investigate the genetic underpinnings of quantitative traits. For better applicability, it may be used as full, partial or half diallel cross. Such hybrids have higher prolificacy, growth rate, better adaptability and survivability. However, among various livestock, it's utilization on cattle/buffalo is limited and most emphasis has been given to swine, poultry and rabbit, due to their high prolificacy and shorter generation interval. Moreover, still a lot of efforts can be done for genetic improvement of undeveloped breed/strains of various livestock species by considering not only the genetic effects but also the reciprocal, combining ability and heterotic effects of diallel crossing. This makes this breeding technique an important tool in the hands of animal breeders for superior/commercial production of animals.

\section{References}

Baas, T. and Christian, L. 1992. Heterosis and Recombination Effects in Hampshire and Landrace Swine: II. Performance 
and Carcass Traits, J. Anim. Sci., 70: 99-110.

Brown, M.A. and Mayeux, H. S. 2005. Postweaning Performance of Hair and Wool Sheep and Reciprocal-crosses on Pasture and in Feedlot. Sheep and Goat Res. J. 20: 60-65.

Browning, R. Jr. and Leite-Browning, M. L. 2011. Birth to weaning kid traits from a complete diallel of Boer, Kiko, and Spanish meat goat breeds semiintensively managed on humid subtropical pasture. J. Anim. Sci. 89:2696-2707.

Cook, W.T., Siegel, P.B. and Hinkelmann, K. 1972. Genetic analyses of male mating behaviour in chickens. II. Crosses among selected and control lines. Behav. Genet., 2: 289-300.

Crusio WE, Kerbusch JM, van Abeelen JHF. 1984. "The replicated diallel cross: a generalized method of analysis". Behavior Genetics., 14 (1): 81-104.

Dearborn, D.D., Gregory, K.E., Cundiff, L.V. and Koch, R.M. 1987. Maternal Heterosis and Grandmaternal Effects in Beef Cattle: Preweaning Traits. Journal of Animal Science. 65 (1): 33-41.

Dubey, A., Jain, A., Gadpaylae, R., Bara, D.K., Yadav, A., Kumar, V. and Sahu, J. 2019. Importance and Utilization of Non-additive Genetic Variance in Farm Animals, J. Entomol. Zool. Stud., 7 (3): 1561-1564.

Duro, S., Okoro, V., Ogundu, U., Udedibie, A., Okoro, C., Ukwu, H. and Ibe, S. 2015. Effect of genotype, sex and parity on growth traits of diallel crossed Nigerian indigenous and exotic pigs., Niger. J. Anim. Prod., 42: 32-40.

Falconer, D. and Mackay, T. 1996. Introduction to Quantitative Genetics, Longman.

Fleming, Alison S. and Kraemer, Gary W. 2019. Molecular and Genetic Bases of
Mammalian Maternal Behavior. Gender and the Genome. 3: 1-14.

García-Casco, J., Fernández, A., Rodríguez, M. C. and Silió, L. 2012. Heterosis for litter size and growth in crosses of four strains of Iberian pig. Livestock Sci. 147:1-8.

Gardner, C. and Eberhart, S. 1966. Analysis and Interpretation of the Variety Cross Diallel and Related Populations. Biometrics. 22:439-452.

Gobena M, Elzo MA and Mateescu RG. 2018. Population structure and genomic breed composition in an AngusBrahman crossbred cattle population. Front. Genet. 9:90.

Gonzalez-Pena, D., Knox, R. V., MacNeil, M. D., Rodriguez-Zas, S. L. 2015. Genetic gain and economic values of selection strategies including semen traits in three- and four-way crossbreeding systems for swine production. J. Anim. Sci., 93:879-891.

Hsu, W. L., Johnson, R. K. 2015. Analysis of 28 generations of selection for reproduction, growth, and carcass traits in swine, J. Anim. Sci., 92:4806-4822.

Iraqi, M., Afifi, E., El-labban, A. and Afran, M. 2007. Heterotic and genetic components in $4 \times 4$ diallel mating experiment for egg production traits in chickens. In: $314^{\text {th }}$ World's Poultry Conference, Sharm El-Sheikh, Egypt. World's Poult. Sci., 29.

Jones, R.B. 1996. Fear and Adaptability in Poultry: Insights, Implications and Imperatives, World's Poult. Sci. J., 52: 131-174.

Kabir, M., Akpa, G.N., Nwagu, B.I. \& Adeyinka, I.A. 2012. Litter traits in a diallel crossing of three rabbit breeds in northern guinea savannah zone of Nigeria. Proc. 10th World Rabbit Congress, Sharm El-Sheikh, Egypt. pp. 67-74.

Kearsey, M.J. 1984. Biometrical analysis of a 
random mating population: a comparison of five experimental designs. Heredity. 20: 205-235.

Kempthorn E.D., and Curnow, R. N. 1961. The partial diallel cross. Biometrics., 17: 229-250.

Kurnianto, E., Arifin, M. and Nugroho, P. 2010. Partial Diallel Cross Analysis among three breeds of pigs for Productive and Reproductive traits. Jurnal Sains dan Teknologi Indonesia. 12:21-24.

Maltecca, C., Khatib, H., Schutzkus, V.R., Hoffman, P.C. and Weigel, K.A. 2006. Changes in conception rate, calving performance, and calf health and survival from the use of crossbred Jersey $\mathrm{x}$ Holstein sires as mates for Holstein dams. J. Dairy Sci. 89:27472754.

Mather, K. and Jinks, J. 1982. Biometrical Genetics. 2nd edition. Chapman and Hall Ltd, London.

Mavrogenis, A. P. 1996. Environmental and genetic factors influencing milk and growth traits of Awassi sheep in Cyprus. Heterosis and maternal effects. Small Ruminant Res. 20:59-65.

McDowelI, R. E., and B. T. McDaniel. 1968. Interbreed Matings in Dairy cattle. III. Economic Aspects. J. Dairy Sci. 51:1649.

Musa, A.A., Orunmuyi, M., Akpa, G.N., Olutunmogun, A.K., Muhammad, H. and Adedibu, I.I. 2015. Diallel analysis for bodyweight involving three genotypes of Nigerian indigenous chickens. S. Afr. J. Anim. Sci., 45 (2): 188-197.

Odeh, F.M., Cadd, G. G. and Satterlee, D. G. 2003. Genetic Characterization of Stress Responsiveness in Japanese Quail. 2.Analyses of Maternal Effects, Additive Sex Linkage Effects, Heterosis, and Heritability by Diallel Crosses. Poultry Science. 82:31-35.
Okoro, V. 2012. Evaluation of Reciprocal, Maternal, Sex-linked and Heterotic Effects on Growth and Reproductive Traits in Pigs. Ph. D Thesis, Michael Okpara University of Agriculture, Umudike.

Okoro, V. and Mbajiorgu, C. 2017a. Diallel cross in swine production: A review. Indian J. Anim. Res., 51(2): 212-218.

Okoro, V. and Mbajiorgu, C. 2017b. Estimates of crossbreeding parameters for growth and conformation traits in Nigerian indigenous and exotic pig breeds. Appli. Ecol. and Environ. Res. 15(4):117-128.

Olson, K.M., Cassell, B. G., McAllister, A.J. and Washburn, S.P. 2009. Dystocia, stillbirth, gestation length, and birth weight in Holstein,Jersey, and reciprocal crosses from a planned experiment. J. Dairy Sci. 92: 61676175.

Orengo, J., Piles, M., Rafel, O. and Ramon, J. 2009. Crossbreeding parameters for growth and feed consumption traits from a five diallel mating scheme in rabbits. J. of Ani. Sci., 89:1896-1905.

Otuma, M.O. and Nwakpu, P.E. 2007. The effect of crossbreeding programmes, season on weight and linear type traits of pre-weaned Nigeria Goats. Ife journal of Science. 9(1): 45-50.

Rastogi, R., W. J. Boylan, W. E. Rempel, and H. F. Windels. 1975. Lamb performance and combining ability of Columbia, Suffolk and Targhee breeds of sheep. J. Anim. Sci. 41:10-15.

Razuki, W.M. and Al-Shaheen, S.A. 2011. Use of full diallel cross to estimate crossbreeding effects in laying chickens, Int. J. of Poultry Sci., 10 (3): 197-204.

Roy, Manoranjan., Senapati, P.K., Pakhira, Manik Ch., Sarkar, U. and Datta, S. 2018. Studies of inheritance of resistance to Haemonchus contortus 
through diallel mating in Garole sheep. J. Entomol. Zool. Stud. 6(1): 569-573.

Saadey, S., Galal, A., Zaky, H. and El-Dein, A. 2008. Diallel crossing analysis for body weight and egg production traits of two native Egyptian and two exotic chicken breeds. Internat. J. of Poultry Sci., 7:64-71.

Sabri, H.M., Khattab, M.S. \& Abdel-Ghany, A.M. 2000. Genetic analysis for body weight traits of a diallel crossing involving Rhode Island Red, White Leghorn, Fayoumi and Dandarawi chickens. Ann. Agric. Sci., 38: 1869-
1883.

Taha, A.E. and Abd El-Ghany, F.A. 2013. Improving Production Traits for Elsalam and Mandarah Chicken Strains by Crossing I- Estimation of Crossbreeding Effects for Growth Production Traits, Alexandria J. of Vety. Sci., 39: 18-30.

Wolf, Jason B and Wade, Michael J. 2009. What are maternal effects (and what are they not)? Philos Trans $R$ Soc Lond B Biol Sci. 364(1520): 1107-1115.

\section{How to cite this article:}

Ashutosh Dubey, Asit Jain, Deepti Kiran Barwa, Aayush Yadav, Manish Kumar Bobade, Vikas Kumar , Anupam Soni and Arvind K. Nanadanwar. 2020. Diallel Crossing in Farm Animals and Poultry: A Review. Int.J.Curr.Microbiol.App.Sci. 9(08): 153-161. doi: https://doi.org/10.20546/ijcmas.2020.908.016 